\title{
Method of accounting the dynamics of technological connections when forming a list of objects for the reconstruction and construction of electrical networks
}

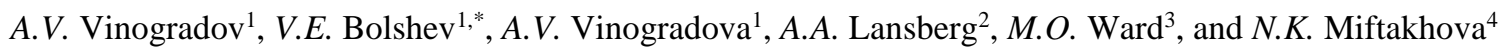 \\ ${ }^{1}$ Federal Scientific Agroengineering Center VIM, 5 1st Institutsky Proezd, Moscow, 109428, Russia \\ ${ }^{2}$ Orel State Agrarian University, 69 General Rodina St., Orel, 302019, Russia \\ ${ }^{3}$ Damascus University, Baramkah, Damascus, 30621, Syria \\ ${ }^{4}$ Kazan State Power Engineering University, 51 Krasnoselskaya St., Kazan, 420066, Russia
}

\begin{abstract}
The paper gives a method of accounting the dynamics of technological connections when forming a list of objects for the reconstruction and construction of electrical networks. The specified method allows maintaining a database of technological connections taking into account the information received from the monitoring systems for electric network operating modes. It makes it possible to assess the dynamics of technological connections by settlements and regions. Based on this, it allows determining the availability of a power reserve for new technological connections and pre-compile a list of objects for reconstruction and construction of electrical network taking into account the dynamics of technological connections.
\end{abstract}

\section{Introduction}

All year round, applications are sent to a power grid company for technological connection of electric energy consumers as well as electric energy production facilities. The service of technological connection is provided in the case of connecting both the first time commissioned and reconstructed energy receiving devices in case of increasing connected capacity and changing the category of power supply reliability, connection points, types of production activities [1].

Technological connection is carried out on the basis of an agreement concluded between a power grid company and a legal or natural person in a timely manner. According to the decree of the Russian Federation [1], the power grid company does not have the right to refuse a consumer a technological connection. In case of unreasonable refusal, a consumer may appeal to the court with a claim for concluding a contract. The investment component is included in the amount of payment for technological connection in order to develop power supply centers and power lines, build electric grid facilities necessary for technological connection. [2]

Lack of accounting dynamics of technological connections when planning modernization, construction or reconstruction of electric networks leads to the fact that the transmission capability of power transmission lines (PTL) and the reserve capacity of substations and transformer substations (TS) become insufficient to connect new consumers. It results in damage to both power grid companies and consumers [3-6]. Power grid companies in this case receive less payment for electricity while consumers cannot expand the technological process and therefore do not receive profit from production.

Losses of the power grid company can be determined as follows $[7,8]$. To do this, the volume of unapproved electric energy $\mathrm{V}$ is calculated associated with the violation of the terms of technological connection. It arises from the lack of reserve transmission capability of power lines or the capacity of substations and TS:

$$
V=D \times \tau,
$$

where $D$ is deficit of capacity or capability, $\mathrm{kW} ; \tau$ is time of exceeding the deadlines established for technological connection implementation.

The cost of unsupplied electricity $C_{\text {unsup. el }}$. is determined by equation (2):

$$
C_{\text {unsup }, \text { el. }}=V \times T,
$$

where $T$ is tariff for electric power transmission service, dollars $/ \mathrm{kWh}$.

The damage to consumers $D_{\text {consumer }}$ is determined by equation (3):

$$
D_{\text {consumer }}=V \times d_{0},
$$

where $d_{0}$ is the specific damage from the lack of electricity supply to consumers, dollars $/ \mathrm{kWh}$.

$d_{0}=1.5-2$ dollars $/ \mathrm{kWh}$ if there is prevailed production load [9] or different categories of agricultural

Corresponding author: vadimbolshev@gmail.com 


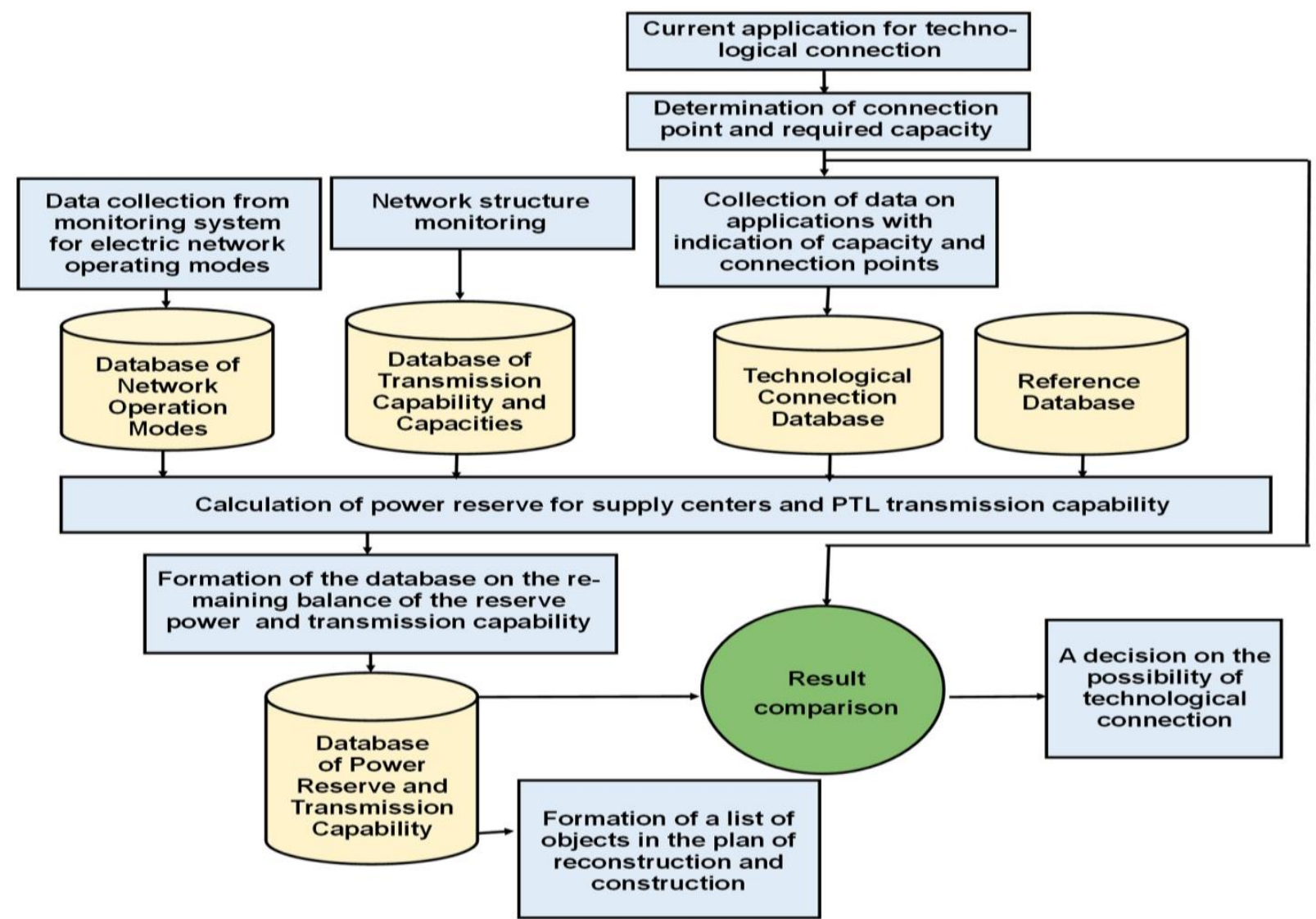

Fig. 1. Method of accounting the dynamics of technological connections when forming a list of objects for the reconstruction and construction of electrical networks.

consumers [10].

The analysis carried out in [11] using the example of Orelenergo (a branch of IDGC of Center, PJSC) showed that there were $83.397 \%$ of applications for technological connection in violation of deadlines in $2013,66.499 \%$ in $2014,55.484 \%$ in $2015,52.606 \%$ in $2016,53.476 \%$ in 2017 . The percentage of fulfillment of applications for technological connection is increasing every year, but remains not high enough. One of the reasons for it is that the dynamics of technological connections is not taken into account when planning investment programs aimed at the reconstruction and development of electric networks. At the same time, the full implementation of this task is possible only with creating intelligent electric networks equipped with monitoring, control and accounting systems [12-16]. It is necessary due to constantly monitor the load of all network objects, monitor the change in this load, determine reserve of power for all substations and TS and power transmission line capability included in the controlled power supply system. So, keeping track of all applications for technological connection and the facts of their implementation is an important task along with controlling other factors affecting the possibility of technological connection on time.

Monitoring systems allow taking into account the dynamics of the growth of loads at the electrical network sections. As a consequence, it gives information about the possibiliffigty of technological connection to a particular section of an electric network, about the need for timely reconstruction of this section to increase its transmission line capability and about the possibility of increasing the power reserve for power sources.

Figure 1 shows a method for taking into account the dynamics of technological connections when forming a list of objects for the reconstruction and construction of electrical networks. It uses data from a system for monitoring electric network operating modes and a system for monitoring consumer connections. The method is as follows. A database of network operation modes is generated on the base of collecting data from monitoring systems. A database is also being formed on the capacities of substations, transformer substations, transmission capability of power transmission lines based on their passport data and acceptable operating modes. To do this, the network structure is monitored and all changes are made to the specified database. The reference database is used in the calculations and contains information on calculation methods and the necessary reference materials. Upon receipt of a new application for technological connection to electrical network, the necessary capacity and connection point are determined. This data is entered into the technological connection database, which takes into account completed and submitted applications for connection. At the same time, data on applications are sorted taking into account the supply centers and power transmission lines. Based on the information available in the databases, the 


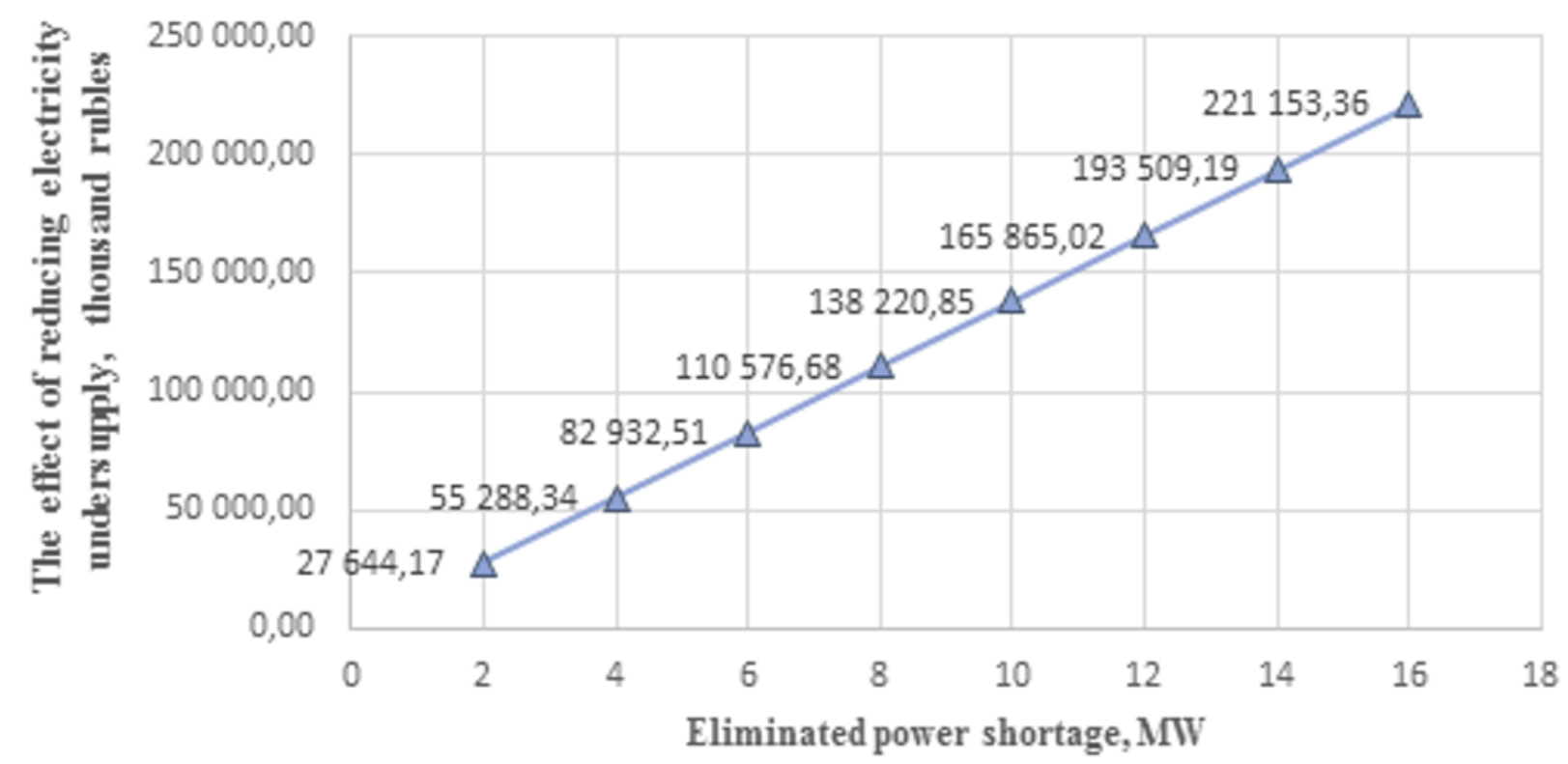

Fig. 2. Dependence of the effect on reducing electricity undersupply due to the elimination of the power shortage for Orelenergo substations.

calculation of the power reserve for the supply centers (substations and TS) and the PTL transmission capability is performed. Since the declared capacity practically does not match the consumed and usually above it, the calculation is performed using the actual values of the consumed power obtained from monitoring systems. Based on the calculated data, a database of power reserve and transmission line capability is formed.

If reserve for a substation, a transformer substation or transmission capability for a power transmission line reach the permissible minimum values, these objects are included in the list of objects for the reconstruction plan, network construction and further into the investment program of a power grid company. In this case, the minimum allowable power reserve is determined depending on the dynamics of the connections to a specific supply center or a power transmission line. That is, with high dynamics of technological connections, the minimum allowable reserve is set larger than with low dynamics of the connections. As for the current connection, the required capacity is compared with the power reserve for the supply center and the transmission capability for PTL the object is planned to connected to. Based on this comparison, a decision is made about the possibility of connecting at this point without reconstructing a substation, a transformer substation or a power transmission line.

The practical result of the implementation of the method is to decrease losses power grid companies due to reducing the time for technological connections.

Figure 2 shows a graph of the effect of reducing electricity undersupply due to the elimination of the power shortage calculated for scarce energy facilities of Orelenergo. There are the substations: 110/10 kV Volodarskaya, 110/10 kV Yuzhnaya, 110/35/10 kV Kulikovskaya, 35/10 kV Zvyaginki, 35/10 kV Streletskaya. The total power undersupply with the existing dynamics of technological connections in for five years it can be up to $16 \mathrm{MW}$.

Timely reconstruction of substations will allow to obtain the indicated effect for power grid companies. For consumers, this effect will be significantly higher since timely technological connection to electric networks will allow them to start the technological process in a timely manner.

\section{Conclusion}

Accounting the dynamics of technological connections to electrical networks requires equipping all power grid facilities with monitoring means that control the current load level of these facilities. The transmission line capability, the power reserve of substations and transformer substations with reference to the point of technological connection are evaluated when each new application for technological connection. If reserve for a substation, a transformer substation or transmission capability for a power transmission line reach the permissible minimum values, these objects are included in the list of objects for the reconstruction plan, network construction and further into the investment program of a power grid company.

\section{References}

[1] On the approval of the Rules for nondiscriminatory access to services for the transmission of electric energy and the provision of these services, the Rules for nondiscriminatory access to services for operational dispatch control in the electric power industry and the provision of these services, the Rules of nondiscriminatory access to the services of the administrator of the trading system of the 
wholesale market and the provision of these services, and the Rules for the technological connection of power receivers of electric energy consumers, facilities for the production of electric energy as well as electric grid facilities owned by grid organizations and other persons, to electric grids, Decree of the Government of the Russian Federation from 27 December 2004 No. 861 (2004)

[2] A.V. Vinogradov, A.V. Vinogradova, A.A. Kuchinov, Vremya osushchestvleniya tekhnologicheskogo prisoedineniya $\mathrm{k}$ elektricheskim setyam kak faktor effektivnosti sistem elektrosnabzheniya [The time of technological connection to electric networks as a factor in the efficiency of power supply systems], Vestnik NGIEI [Bulletin of the NIEGI] 6, 73, 5460 (2017)

[3] H.L. Willis, Power distribution planning reference book (CRC press, 2004)

[4] J.J. Grainger, W.D. Stevenson, W.D. Stevenson, Power system analysis (McGraw-Hill Inc, Singapore, 2003)

[5] E. Gracheva, A. Alimova, Calculation Methods and Comparative Analysis of Losses of Active and Electric Energy in Low Voltage Devices, International Ural Conference on Electrical Power Engineering (UralCon), 361-367. DOI: 10.1109/URALCON.2019.8877627 (2019)

[6] A. Vinogradov, A. Vinogradova, V. Bolshev, A.I. Psarev, Sectionalizing and Redundancy of the $0.38 \mathrm{kV}$ Ring Electrical Network: Mathematical Modeling Schematic Solutions, International Journal of Energy Optimization and Engineering (IJEOE) $\quad 8, \quad 4, \quad 15-38 . \quad$ DOI: 10.4018/IJEOE.2019100102 (2019)

[7] A. Vinogradov, A. Vasiliev, V. Bolshev, A. Semenov, M. Borodin, Time factor for determination of power supply system efficiency of rural consumers, Handbook of Research on Renewable Energy and Electric Resources for Sustainable Rural Development (Hershey, PA: IGI Global, 394-420, 2018). DOI: 10.4018/9781-5225-3867-7.ch017

[8] A. Vinogradov, V. Bolshev, A. Vinogradova, M. Borodin, A. Bukreev, I. Golikov, Mobile Measuring Complex for Conducting an Electric Network Survey, Handbook of Research on Energy-Saving Technologies for Environmentally-Friendly Agricultural Development (Hershey, PA: IGI Global, 243-267, 2020)

[9] V.Ya. Khorolsky, M.A. Taranov, D.V. Petrov, Tekhniko-ekonomicheskie raschety raspredelitel'nyh elektricheskih setej [Technical and economic calculations of distribution electric networks] (Terra Print, Rostov-on-Don, Russia, 2009)

[10] N.M. Zul, A.M. Agalarov, N.F. Molosnov, Metodicheskie rekomendacii po opredeleniyu ushcherba sel'skohozyajstvennomu proizvodstvu ot pereryvov $v$ podache elektroenergii [Guidelines for determining damage to agricultural production from interruptions in the supply of electricity] (VIESH, Moscow, Russia, 1974)

[11] A.V. Vinogradov, M.V. Borodin, Yu.A. Volchenkov, ZH.V. Peshehonova, Sovershenstvovanie deyatel'nosti po energosberezheniyu $i$ po osushchestvleniyu tekhnologicheskih prisoedinenij filiala OAO "MRSK CENTRA" - "ORYOLENERGO" [Improvement of energy saving and technological connections for the branch of ORELENERGO, a branch of IDGC of Center] (Publishing House of Orel State Agrarian University, Oryol, Russia, 2015)

[12] J.A. Momoh, Smart grid design for efficient and flexible power networks operation and control, Power Systems Conference and Exposition, PSCE '09, 1-8. DOI: 10.1109/PSCE.2009.4840074 (2009)

[13] A. Ipakchi, F. Albuyeh, Grid of the future, IEEE Power and Energy Magazine 7, 52-62. DOI: 10.1109/MPE.2008.931384 (2009)

[14] A. Vinogradov, V. Bolshev, A. Vinogradova, T. Kudinova, M. Borodin, A. Selesneva, N. Sorokin, A System for Monitoring the Number and Duration of Power Outages and Power Quality in $0.38 \mathrm{kV}$ Electrical Networks, In Vasant P., Zelinka I., Weber GW. (eds) Intelligent Computing \& Optimization. ICO 2018. Advances in Intelligent Systems and Computing 866, 1-10. DOI: 10.1007/978-3-030-00979-3 1 (2019)

[15] A. Vinogradov, A. Vinogradova, I.O. Golikov, V. Bolshev, Adaptive Automatic Voltage Regulation in Rural $0.38 \mathrm{kV}$ Electrical Networks, International Journal of Emerging Electric Power Systems 20, 3. DOI: 10.1515/ijeeps-2018-0269 (2019) 